Research Article

Sonia Ait-Amar*, Daniel Roger, and Serghei Savin

\title{
Aging monitoring of electrical machines using winding high frequency equivalent circuits
}

https://doi.org/10.1515/phys-2019-0069

Received May 29, 2019; accepted Jun 28, 2019

\begin{abstract}
This study defines a monitoring method based on impedance analysis in the upper part of the spectrum. It focuses on the analysis of the high frequency behavior of electrical machines windings considering the turn-toturn capacitance variations (delta-C) due to insulation aging. An equivalent circuit is automatically generated from the turn arrangements in coils; parameters are computed considering the coil shape and the characteristics of insulation materials. PSpice analysis of the equivalent circuit yields the resonance frequencies to be monitored. With this software and a database giving the relationship between the turn-to-turn capacitance variation delta- $\mathrm{C}$ and the reduction of insulation performances due to aging, it is possible to build a monitoring system able to produce an alert when the probability of failure becomes higher than a predetermined level.
\end{abstract}

Keywords: AC machine winding, aging, frequency analysis, monitoring, preventing maintenance

PACS: 84.30.Jc, 84.37.+q

\section{Introduction}

It is well known that, for an electrical motor fed by Pulse Width Modulation (PWM) electronic converter, high voltage spikes are applied on the windings after each fastfronted voltage pulse. These constraints may produce an important aging acceleration when voltage spikes cause Partial Discharges (PD) in the machine Electrical Insulation System (EIS). Indeed, the ionization of air in the microscopic voids remaining between turns in the motor EIS cause a strong aging acceleration of the thin organic in-

\footnotetext{
`Corresponding Author: Sonia Ait-Amar: Univ. Artois, EA4025, LSEE, EA4025, F-62400, Béthune, France; Email:

sonia.aitamar@univ-artois.fr

Daniel Roger, Serghei Savin: Univ. Artois, EA4025, LSEE, EA4025, F-62400, Béthune, France
}

sulation layers of the enameled copper wire used to build the motor coils. The aging monitoring of the EIS of electrical machines is an important issue for preventive maintenance programs that ensure the availability and the reliability of equipments [1]. Currently, several monitoring machines techniques exist, but most of them detect a proven failure such as a turn-to-turn short; they do not predict it before it occurs. Previous studies prove the increase of the turn-to-turn capacitance during aging and the correlation of this indicator with insulation aging [2, 3]. A critical turn-to-turn capacitance variation can be defined; it can be used in a supervision system for signaling the insulation aging acceleration due to the PD appearance. This capacitance variation delta-C determines changes in winding resonance frequencies in the upper part of the spectrum, parameter that can be used by a specific motor diagnostic systems. The objective is to define an automatic simulation tool, which will be able to calculate the variations of resonance frequencies by using the previously defined critical delta-C and the motor winding topology.

In this study, we propose a simulation tool based on a model that uses an equivalent circuit, which is automatically generated from the coil topology. The parameter determination is a very important step for a correct estimation of resonance frequencies variations. A coil of a known geometry has been considered as a validation example; the equivalent circuit is automatically created from the coil geometry and parameters determination method using finite element software is proposed.

\section{Simulation model description}

The resonance frequencies of electrical motors are determined using PSpice. The block diagram of the simulation algorithm is presented in Figure 1.

The coils are presented by an equivalent circuit made of discrete RLC elements [4]. Each element of this equivalent circuit represents one turn or part of a turn much smaller than the wavelength, calculated at the highest resonance frequency. For small machines, a basic element of this circuit is a turn of a coil. For larger coils sizes, a finer

¿ Open Access. (c) 2019 S. Ait-Amar et al., published by De Gruyter. (Cc) BY 4.0 License 


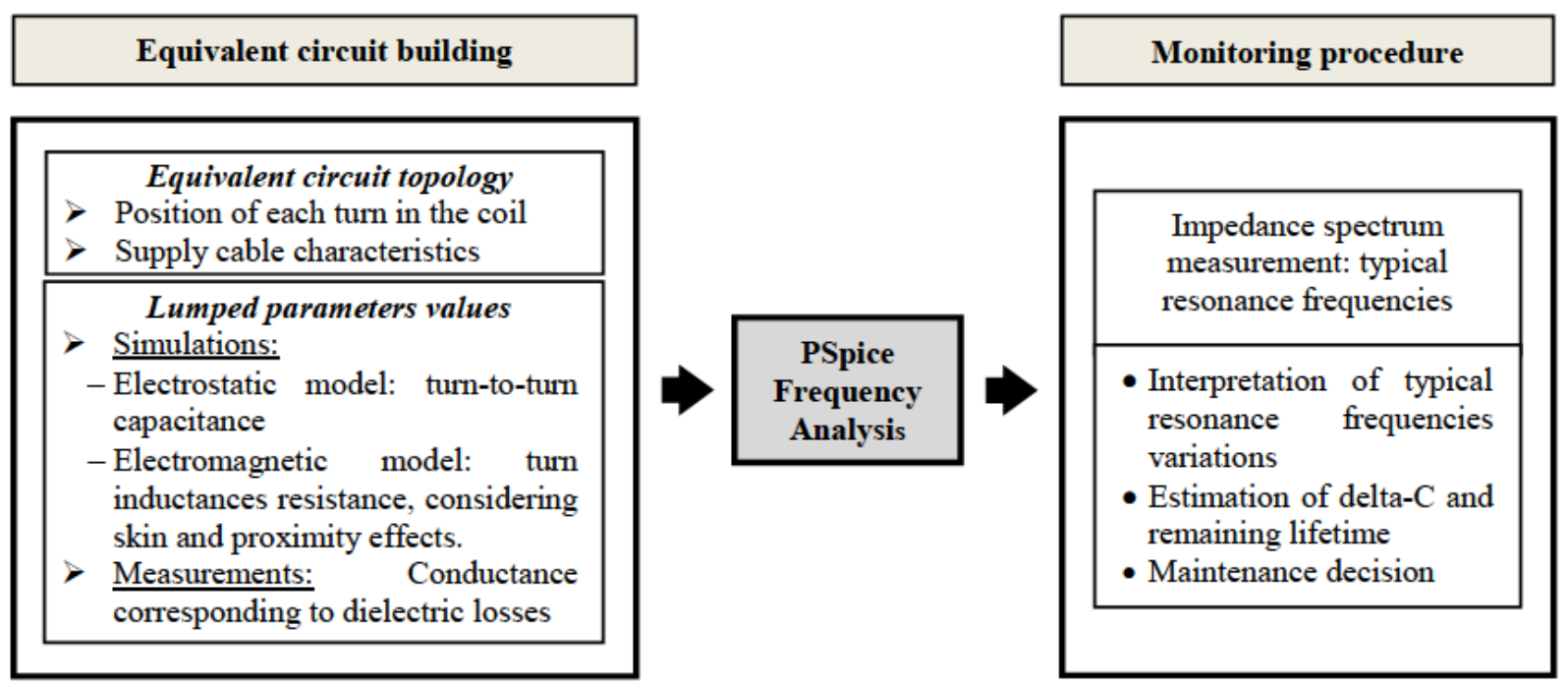

Figure 1: Motor aging monitoring principle.

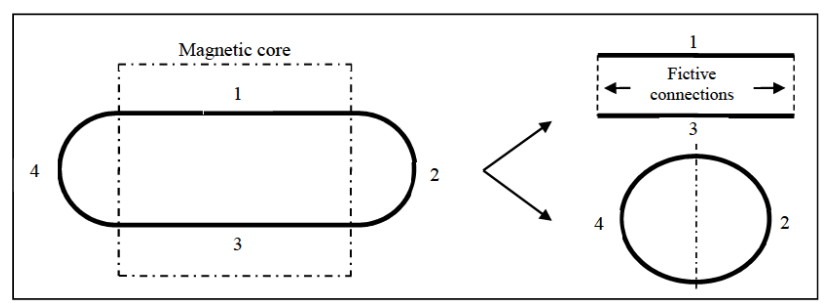

Figure 2: Electrical motor winding divided into two parts for parameters calculation.

cutting is required, one element for a half-turn or for a quarter-turn for example.

The usual PSpice input interface is a circuit editor used to define the various components of the circuit and their connections at nodes. This "man-machine" interface creates a text file called "Netlist 1 " which translates the input circuit in a list describing the nodes and their interconnections. After forming the matrix corresponding to the circuit, the numerical calculations are executed. The result is a text output file "Netlist 2", its analysis can be made using the PSpice graphical interface. For a standard motor coil of approximately 50 turns, the equivalent circuit has several hundreds of elements; it becomes too complex for the graphical input interface of PSpice, which is replaced by another one written in MatLab environment. This interface builds the file "Netlist 1" from the relative positions of turns in a coil and the parameters of each turn. For a $\mathrm{N}$-turn coil, the topology of the turns inside the coils is described by a NxN matrix made of Boolean elements that describes the adjacency of the turns. The lumped parame- ters determined for one turn are affected to the equivalent circuit using this matrix.

This approach allows to build a fairly detailed equivalent circuit of a motor coil, valid for high frequencies; however, it is very important to introduce the relevant basics parameters of eachelement of the circuit corresponding to one turn, half a turn or a quarter-turn depending of the machine size.

\section{Model parameters}

For small and medium size motors, the basic element corresponds to one turn of a coil. The self-inductances of the turns, the mutual coupling between them, the turn-to-turn capacitances and those between turns and ground determine the values of the resonance frequencies. The resistances correspond to damping effects.

Generally speaking, the motor windings are made with an enameled copper wire. The insulation of such a wire is made with two organic layers; the first one is made of Polyester-imide (PEI) and the second one of polyamideimide (PAI); the total thickness of the insulating layer is $35 \mu \mathrm{m}$. The coils are often impregnated by an organic varnish. A cheaper solution exists; it uses a specific enameled wire that has a third layer made of an aromatic polyamide for thermo bonding.

For this analysis, each elementary motor coil can be divided into four parts (Figure 2) combined in pairs. For parts 1 and 3 located in the slots of the laminated core, the parameters are computed considering fictive connections 

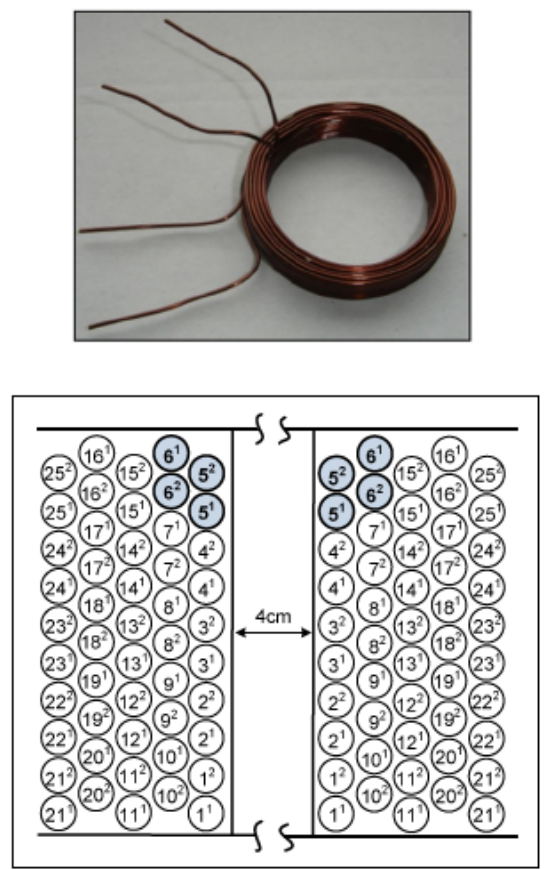

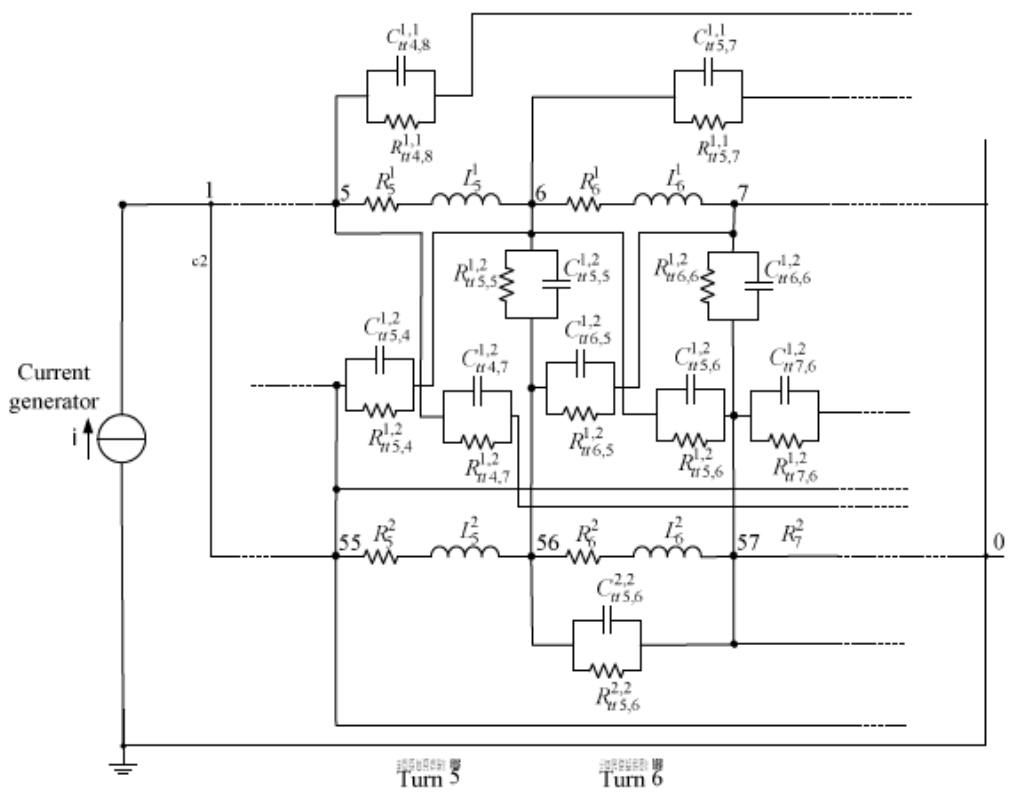

Figure 3: Small part illustration of the experimental coil equivalent circuit (turns 5 et 6).

at each end of the core. The inductance of such a coil in a laminated magnetic core decreases with frequency. At high frequencies the skin effect in the laminations reduces strongly; the fluxes and the corresponding inductances are very low $[5,6]$. For high frequencies, the preponderant magnetic effects are due to winding end-connections (Figure 2, parts 2 and 4). Magnetic parameters can be computed with 2D simulation software based on finite elements using axisymmetric coordinates and considering a circular coil. Skin depth and proximity effects in the copper wires must be considered for determining turn self and mutual inductances and resistances $[7,8]$.

The capacitances and the corresponding dielectric losses must also be considered. The turn-to-turn capacitances correspond to the major electrostatic effects in the winding, but the turn-to-ground capacitances must be included in the model for the straight parts 1 and 3 of coils. The Table 1 summarizes the coil parameters and their dominant effects.

The study of the variation of resonance frequencies $\left(\Delta \mathrm{F}_{\text {res }}\right)$, depending on the turn-to-turn capacitance variationshas been performed on a simplified model: a circular coil with a $4 \mathrm{~cm}$ internal diameter. The experimental coil is wound with two parallel wires in order to provide an indirect measurement of turn-to-turn capacitance. The turn-toturn capacitance variations $\left(\Delta \mathrm{C}_{\text {turn-to-turn }}\right)$ has been correlated to the Partial Discharge Inception Voltage (PDIV)fora large number of standard twisted specimens and standard
Table 1: Coil parameters.

\begin{tabular}{lcc}
\hline $\begin{array}{l}\text { Magnetic } \\
\text { parameters }\end{array}$ & $\begin{array}{c}\text { Self and mutual } \\
\text { inductances }(\mathrm{L}, \mathrm{M})\end{array}$ & $\begin{array}{c}\text { Series Résistance } \\
\left(\mathrm{R}_{S}\right) \text { skin and } \\
\text { proximity effects }\end{array}$ \\
\hline $\begin{array}{ccc}\text { Electrostatic } \\
\text { parameters }\end{array}$ & $\begin{array}{c}\text { Turn-to-turn and } \\
\text { turn-to-ground } \\
\text { capacitances }\end{array}$ & $\begin{array}{c}\text { Parallel resistance } \\
\left(\mathrm{R}_{P}\right)\end{array}$ \\
$\begin{array}{c}\text { Dominant } \\
\text { effects }\end{array}$ & $\begin{array}{c}\text { Winding resonance } \\
\text { frequencies }\end{array}$ & Damping effects \\
\hline
\end{tabular}

thermal accelerated aging procedures; a clear correlation between the capacitance increase and the reduction of the PDIV has been established [2]. The arrangement of turns in the experimental coils is presented in Figure 3. In spite of the reduced number of turns (25 turns), the equivalent circuit is quite complex. A portion of this equivalent circuit (turns 5 and 6) is shown in Figure 3. Each turn is characterized by a resistance and an inductance connected in series. Mutual inductances are not represented but they are considered. For adjacent turns, a capacitance and a parallel resistance characterizing the dielectric losses is added in the equivalent circuit. 


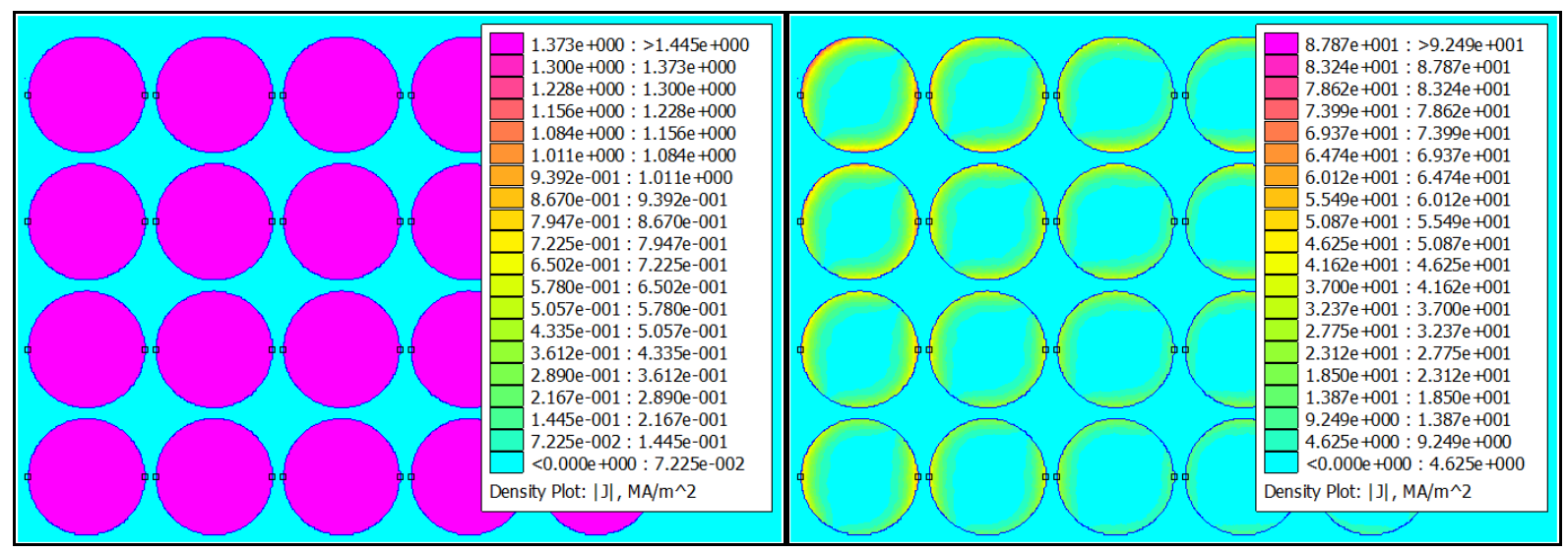

a) $100 \mathrm{~Hz}$

b) $1 \mathrm{MHz}$

Figure 4: The current density distribution at $100 \mathrm{~Hz}$ and $1 \mathrm{MHz}$ for 25 turns coil.

\subsection{Calculation of magnetic parameters (series part of the equivalent circuit)}

The inductances of experimental coils are determined with the finite element method using the FEMM software. The mesh is very fine in order to take into account the skin effect and the proximity effect in copper. It is smaller than $10 \mu \mathrm{m}$ around the surface of the wires (for cooper wire, the thickness skin is $66 \mu \mathrm{m}$ at $1 \mathrm{MHz}$ and $21 \mu \mathrm{m}$ at $10 \mathrm{MHz}$ ).

Figure 4 shows the skin and proximity effect by presenting the current density in the coil conductors at $100 \mathrm{~Hz}$ and $1 M H z$. The simulations were made for an imposed average current of $1 \mathrm{~A}$. It can be seen that the current density in the conductors is uniform and approximately equal to $1.37 \mathrm{MA} / \mathrm{m}^{2}$ at $100 \mathrm{~Hz}$. At $1 \mathrm{MHz}$, the software gives the overall result, which includes the skin effect and the proximity effect. In Figure 4b, a much higher current density can be observed in peripheral areas of the conductors, which is in order of $87 \mathrm{MA} / \mathrm{m}^{2}$ for the same average imposed current. The current density is almost zero in the wire center.

The self and mutual inductances are determined by applying a $1 A$ current to the turn for which the inductance is calculated. For the other turns the current is $0 A$. FEMM calculates the magnetic field lines and superimpose the induced current to the source current and the voltage across the windings. The FEMM post-processor gives the self-inductance of supplied turn and all mutual inductances. The simulations are performed in the same manner to determine each turn parameters.

For the simulated circular coil in air, the inductances values are almost the same for all the turns with a slight increase of about $2.5 \%$ for outer layer turns. The average value is considered for the PSpice coil model.
The mutual coupling depends on the relative position of the turns. In order to simplify, the model considers only two values, the mutual coupling between turns of the same strand (k1) and the average of mutual coupling between the other turns of the coil (k2). This distinction reduces the complexity of the model and yields results very close to the experimental resonance frequencies.

For calculating series resistance, the two effects (skin and proximity) are taken into account. In this case all the turns are supplied with a $1 A$ current by imposing a series connection between them. The post processor provides the total resistance of the coil. For a single turn, it is considered that all turns are identical and therefore the total resistance is divided over the number of turns.

\subsection{Electrostatic parameters calculation (parallel part of the equivalent circuit)}

The parallel parameters characterize the capacitive coupling between turns. They are represented by the capacitances between the individual turns of the coil and their parallel resistances characterizing the dielectric losses. The calculation of turn-to-turn capacitance is made with the Electrostatic solver of FEMM. For this calculation, the position of each turn, the dimensions and the dielectric characteristics in terms of relative permittivity of insulation layers are important. The $1 V$ source is imposed on any wire that is located in the coil, the other are grounded. The capacitance between two conductors separated by an insulating layer is defined as the ratio between the quantity of electric charges on the conductors and the corresponding voltage. The software computes the electric field and 
Table 2: Parameters of the experimental coil.

\begin{tabular}{|c|c|c|c|c|}
\hline \multirow{6}{*}{$\begin{array}{l}\text { Computed values } \\
\text { (FEMM) }\end{array}$} & & $4,3 \mathrm{MHz}$ & $35 \mathrm{MHz}$ & Difference $(\%)$ \\
\hline & Turn inductance - L $(n H)$ & 73.2 & 71.1 & 2.8 \\
\hline & Turn resistance - R $(\Omega)$ & 0.49 & 1.51 & 67 \\
\hline & Mutual coupling coefficient - k1 & 0.85 & 0.83 & 2.3 \\
\hline & Mutual coupling coefficient - k1 & 0.5 & 0.47 & 6 \\
\hline & \multicolumn{4}{|c|}{ Turn-to-turn capacitance: $\mathrm{C}=15 p F$} \\
\hline \multirow{2}{*}{$\begin{array}{c}\text { Available } \\
\text { measurements }\end{array}$} & Dielectric losses eq. resistance - $\mathrm{Rp}(k \Omega)$ & 200 & 50 & 75 \\
\hline & Turn resistance $-\mathrm{R}(\Omega)$ & 0.51 & 1.54 & 67 \\
\hline
\end{tabular}

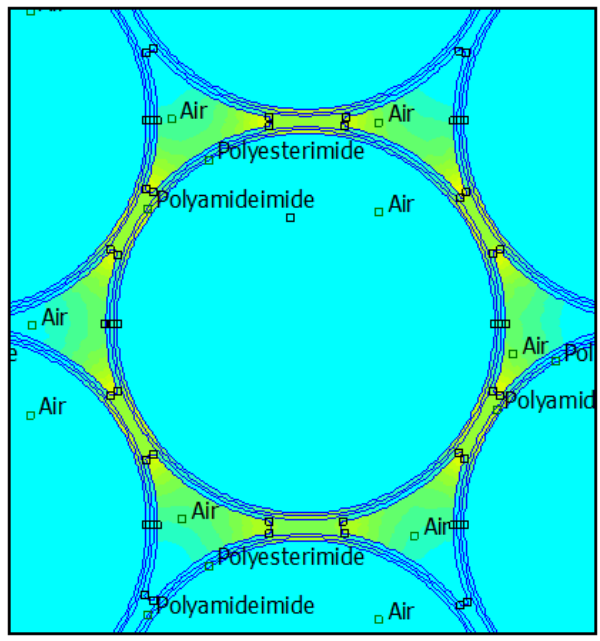

a) Inner coil turn

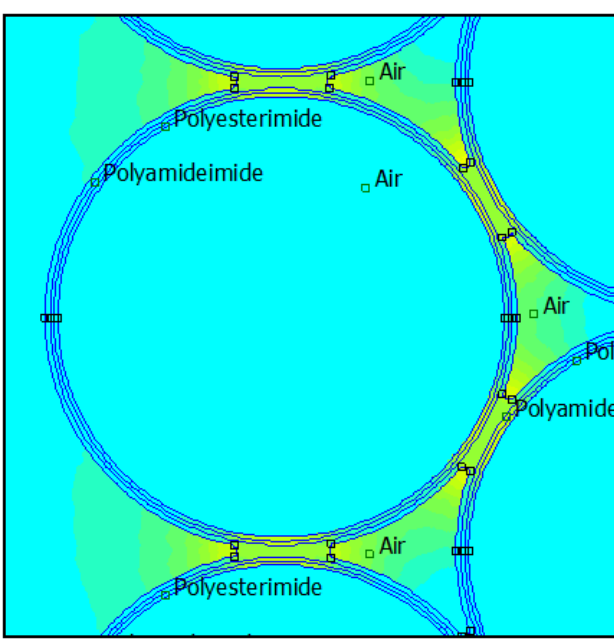

b) Outer coil turn

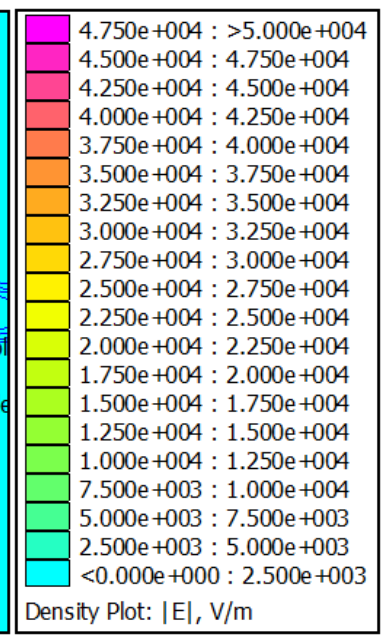

c) Legend of a) and b)

Figure 5: Distribution of the electric field: a) for an inner coil turn; b) for an outer coil turn.

charges on all conductors and calculates the turn-to-turn capacitance.

For the experimental coil, there is no capacitance between turns and ground. Previous studies have shown that a given turn have capacitances with the turns of the first layer surrounding it, the capacitance with the other turns is negligible [4]. For determining the turn-to-turn capacitance of the circular tested coil, this latter is represented in axisymmetric coordinates by wires covered with an insulation of dimensions given in IEC 60317-0-1 standard [9], by taking into account the permittivity given by the wire manufacturer: $\epsilon_{r}=3.5$ for polyester-imide (PEI) and polyamide-imide (PAI). The relative permittivity of aromatic polyamide is 4.5. Two cases are presented: the supplied turn $(1 \mathrm{~V})$ is situated in the coil middle and is surrounded by adjacent turns. In the second case, the supplied turn is in the outer layer of the coil and is surrounded only by a side (Figure 5). The turn-to-turn capacitance is slightly different for external and internal layers of the coil (about 5\%). This effect is due to the different distribution of the electric field, but these differences are negligible.

The parallel resistance is very difficult to compute because it corresponds to complex phenomena in the insulation layers. This parameter is estimated from measurements made on the two independent wires of the experimental coil.

The Table 2 summarizes the equivalent circuit parameters. It can be seen that the inductances are practically independent on frequency; conversely the resistances are dependent. Consequently, the model based on the equivalent circuit can be used for determining resonance frequencies but not damping effects. 


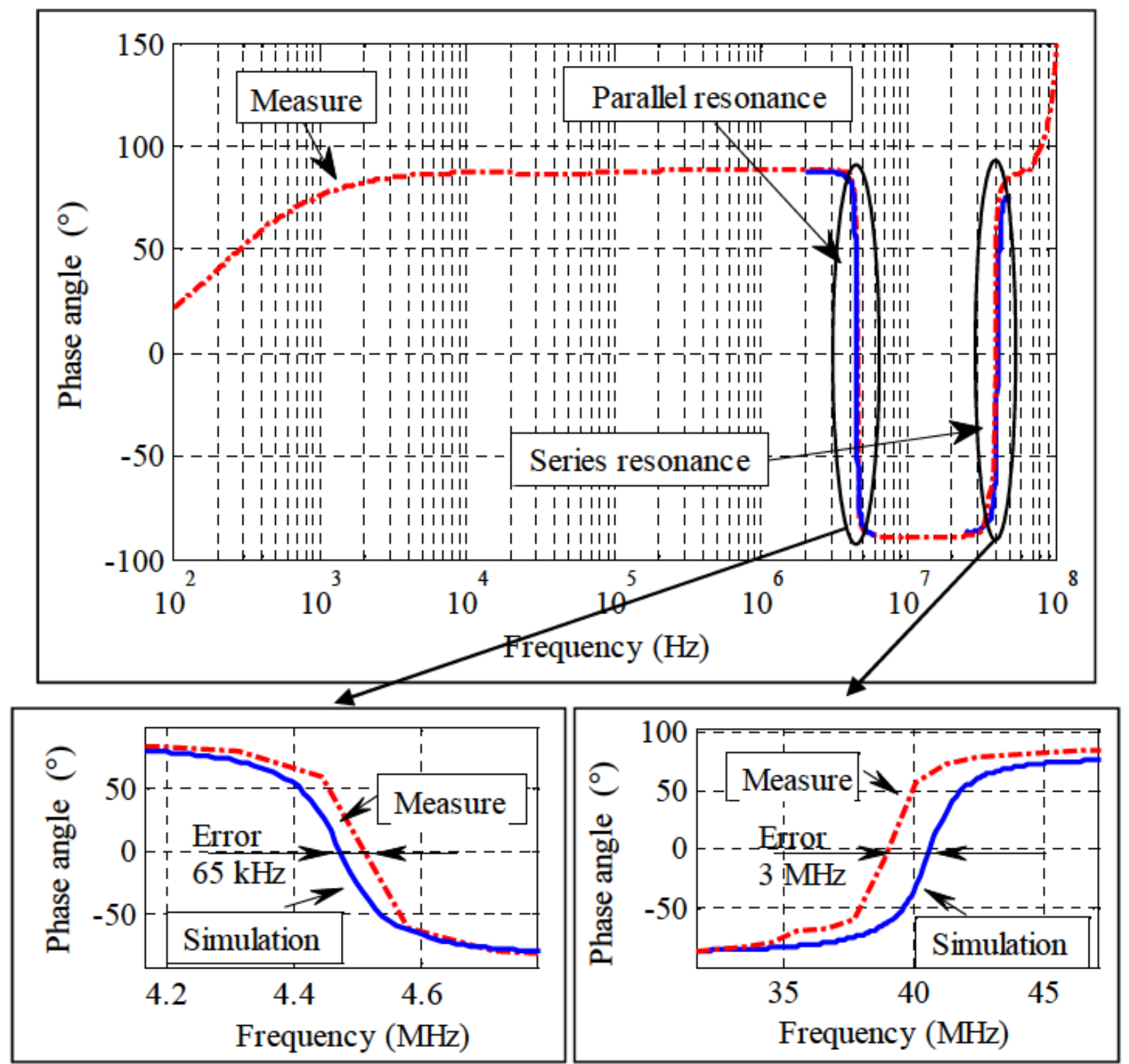

Figure 6: Coil frequency response represented by the phase angle of the complex impedance: results of experimental tests and simulations.

\section{Model validation and estimation of changes in resonance frequencies due to variations in turn-to-turn capacitance}

The simulations are performed for small frequency bands around the first two resonance frequencies. Simulation and experimental results are shown in Figure 6. They are superimposed on theglobal curve but zooms allow us to appreciate the accuracy of the model. For the first resonance, the absolute error is close to $65 \mathrm{kHz}$ which fact a relative error of $1.5 \%$. For the second resonance, the difference between the measured and simulated results is more impor$\operatorname{tant}(3 \mathrm{MHz})$, with a relative difference equal to $7.5 \%$. This result confirms that the model parameters are more difficult to determine as the frequency increases.

The model can be used to determine the variations of resonance frequencies due to changes measured on the turn-to-turn capacitance (20\%) that correspond to a decrease of the PDIV that makes possible the apparition of PD in a standard machine winding fed by a PWM inverter $[2,10]$. The variations of the first and second resonance frequencies corresponding to different values of the turn-to-turn capacitances are shown in Figure 7. The ca- 


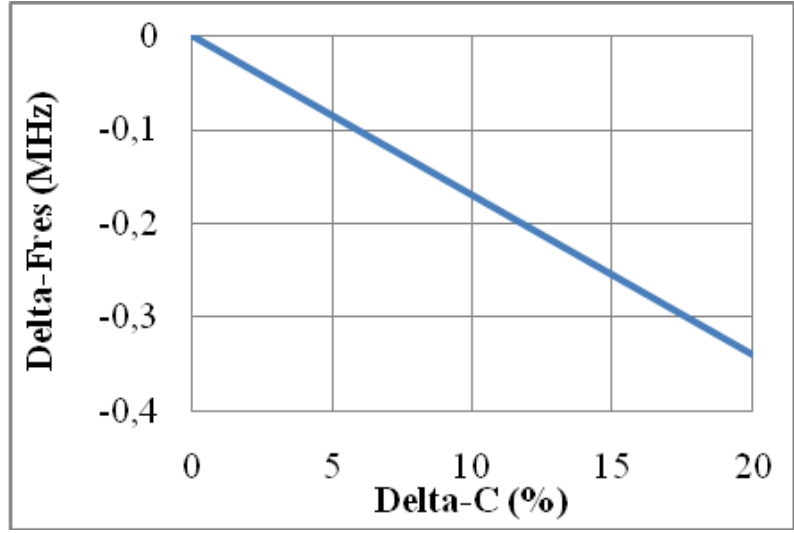

a) First resonance frequency

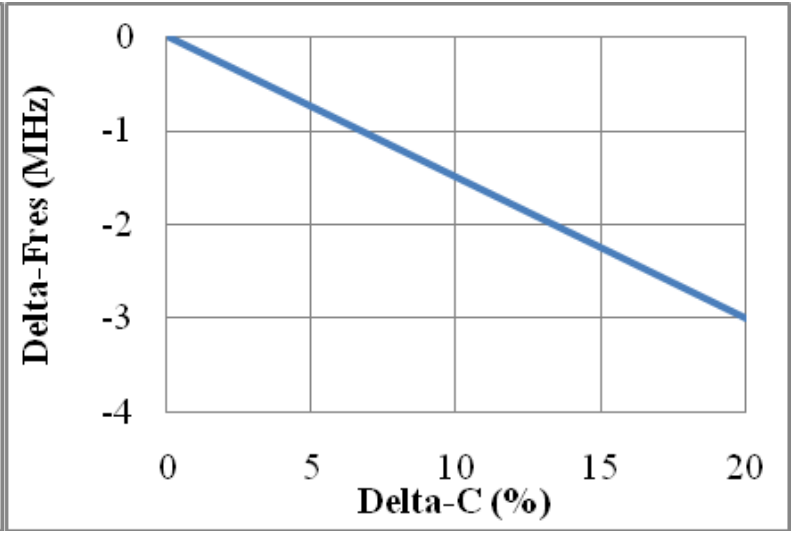

b) Second resonance frequency

Figure 7: The correlation between Resonance frequencies and turn-to-turn capacitance variations.

pacitance increases from the initial value measured on a new coil $\left(\mathrm{C}_{\text {turn-to-turnt }}\right)$ to a value $20 \%$ higher. We note that for the maximum variation of the turn-to-turn winding capacitance $(20 \%)$, the frequency decrease is $340 \mathrm{kHz}$ for the first resonance frequency and $3 \mathrm{MHz}$ for the second one. These variations of resonance frequencies are significant. They can be used by a monitoring system able to give an alert when the PDIV decrease, that corresponds to the beginning of strong acceleration of the motor aging process due to PD in the winding insulation.

Fourteen identical experimental coils have been made and tested using standard cycles at $280^{\circ} \mathrm{C}$ during 24 hours [11] providing a controlled acceleration of coil aging. The measurements of the two resonance frequencies are in good concordance with the predictions of the proposed method base on a lumped parameter equivalent circuit [10].

\section{Conclusion}

The electrical machines insulation aging can be characterized by the increase of the turn-to-turn capacitance in windings that induce changes in resonance frequencies in the $\mathrm{MHz}$ range. This study presents a simulation tool that can determine changes in the resonance frequencies due to critical changes in capacitance. To obtain reliable results, an accurate and robust characterization of the coil parameters is necessary. For this purpose, a large part of this study is dedicated to general parameters determination of an elementary experimental coil.
The simulation results are compared with measurement ones. The good concordance between the simulation and measurement results validates the simulation model and the parameters determination principle.

Finally, the critical resonance frequencies variations corresponding to critical capacitance variations are defined and will be used to indicate the probability of faster insulation aging, due to the appearance of PD in the motor insulation.

\section{References}

[1] Kaufhold M., Borner G., Eberhardt M., Speck J., Failure mechanism of the interturn insulation of low voltage electric machines fed by pulse-controlled inverters, IEEE Electr. Insul. Mag., 1996, 2(2), 9-16

[2] Savin S., Ait-Amar S., Roger D., Turn-to-Turn Capacitance Variations Correlated to PDIV for AC Motors Monitoring, IEEE Trans. Dielec. Elec. Insul., 2013, 20 (1), 34-41.

[3] Roger D., Duchesne S., Ait-Amar S., Notingher P., Turn-to-turn capacitance used as an indicator of winding insulation aging, In: Studies in Applied Electromagnetics and Mechanics, IOS Press, 2010.

[4] Mihaila V., Duchesne S., Roger D., A Simulation Method to Predict the Turn-to-turn Voltage Spikes in a PWM Fed Motor Winding, IEEE Trans. Dielec. Elec. Insul., 2011, 18(5), 1609-1615.

[5] Lammeraner J., Stafl M., Eddy currents, ILIFFE Books Ltd ed. London, 1966.

[6] Duchesne S., Napieralska-Juszczak E., Roger D., Eddy current influence on electromagnetic emissions of laminated cores, COMPEL, 2007, 26(4), 986-1004.

[7] Nan X., Sullivan C. R., Simplified high-accuracy calculation of eddy-current loss in round-wire windings, Proceedings of IEEE 35th Annual Power Electronics Specialists Conference, 2004, 873-879. 
[8] Tourkhani F., Viarouge P., Accurate analytical model of winding losses in round Litz wire windings, IEEE Trans. Magnet., 2001, 37(1), 538-543.

[9] Standard IEC 60317-0-1, Specifications for particular types of winding wires - Part 0-1: General requirements - Enamelled round copper wire, 2013.
[10] Savin S., Nouvel indicateur de vieillissement de l'isolation interspires des machines électriques utilisées en aéronautique, $\mathrm{PhD}$ thesis, Artois University, Bethune, France, 2013 (in French).

[11] Standard IEC 60172, Test procedure for the determination of the temperature index of enamelled winding wires, 2015. 